\title{
Dynasore suppresses cell proliferation, migration, and invasion and enhances the antitumor capacity of cisplatin via STAT3 pathway in osteosarcoma
}

\author{
Binlong Zhong (1)', Deyao Shi', Fashuai Wu', Shangyu Wang ${ }^{1}$, Hongzhi Hu', Cheng Cheng ${ }^{1}$, Xiangcheng Qing ${ }^{1}$, \\ Xin Huang ${ }^{1}$, Xueying Luo ${ }^{2}$, Zhicai Zhang ${ }^{1}$ and Zengwu Shao ${ }^{1}$
}

\begin{abstract}
Osteosarcoma (OS) is the most common malignant bone tumor. The prognosis of metastatic and recurrent OS patients still remains unsatisfactory. Cisplatin reveals undeniable anti-tumor effect while induces severe side effects that threatening patients' health. Dynasore, a cell-permeable small molecule that inhibits dynamin activity, has been widely studied in endocytosis and phagocytosis. However, the anti-tumor effect of dynasore on OS has not yet been ascertained. In the present study, we suggested that dynasore inhibited cell proliferation, migration, invasion, and induced G0/G1 arrest of OS cells. Besides, dynasore repressed tumorigenesis of OS in xenograft mouse model. In addition, we demonstrated that dynasore improved the anti-tumor effect of cisplatin in vitro and in vivo without inducing nephrotoxicity and hepatotoxicity. Mechanistically, dynasore repressed the expression of CCND1, CDK4, p-Rb, and MMP-2. Furthermore, we found that dynasore exerts anti-tumor effects in OS partially via inhibiting STAT3 signaling pathway but not ERK-MAPK, PI3K-Akt or SAPK/JNK pathways. P38 MAPK pathway served as a negative regulatory mechanism in dynasore induced anti-OS effects. Taken together, our study indicated that dynasore does suppress cell proliferation, migration, and invasion via STAT3 signaling pathway, and enhances the antitumor capacity of cisplatin in OS. Our results suggest that dynasore is a novel candidate drug to inhibit the tumor growth of OS and enhance the anti-tumor effects of cisplatin.
\end{abstract}

\section{Introduction}

Osteosarcoma (OS) remains the most common malignant bone tumor with a preference for the metaphysis of tubular long bones, especially in distal femur, proximal tibia and humerus, and most occurs in adolescents and teenagers. The incidence of OS is only $1.7-4.4$ per million ${ }^{1}$, but with great invasive and metastatic capacity, the progression of OS squint towards disability and death,

\footnotetext{
Correspondence: Zhicai Zhang (zhicaizhang@126.com) or

Zengwu Shao (szwpro@163.com)

'Department of Orthopaedics, Union Hospital, Tongji Medical College, Huazhong University of Science and Technology, 1277 JieFang Avenue Wuhan 430022, China

${ }^{2}$ Tongji Medical College, Huazhong University of Science and Technology, Wuhan Mental Health Centre, Wuhan Hospital for Psychotherapy, Wuhan, China

Edited by A. Stephanou
}

which causes substantial psychological and financial burdens. By following the treatments of neoadjuvant chemotherapy and surgical resection followed by adjuvant chemotherapy, the 5-year even-free survival rate reaches $60-70 \%$ in patients with localized, non-metastasis OS $^{2}$. However, most patients present metastasis, usually in lung, when first diagnosed, and encounter poor prognosis with 5-year survival rate of $20-30 \%$ even they adhere to standard therapy strategies ${ }^{3,4}$. Even worse, the diverse side-effects limit the choices and usages of anti-tumor drugs in OS chemotherapy. As one of the crucial drugs in OS chemotherapy, cisplatin exerts a potent anti-OS activity, but at the same time, causes apparent side effects including nephrotoxicity, hepatotoxicity, ototoxicity, and myelosuppression ${ }^{5,6}$. Cisplatin induced nephrotoxicity is the most common side effect, which is

\section{(c) The Author(s) 2019}

(c) (i) Open Access This article is licensed under a Creative Commons Attribution 4.0 International License, which permits use, sharing, adaptation, distribution and reproduction c. in any medium or format, as long as you give appropriate credit to the original author(s) and the source, provide a link to the Creative Commons license, and indicate if changes were made. The images or other third party material in this article are included in the article's Creative Commons license, unless indicated otherwise in a credit line to the material. If material is not included in the article's Creative Commons license and your intended use is not permitted by statutory regulation or exceeds the permitted use, you will need to obtain permission directly from the copyright holder. To view a copy of this license, visit http://creativecommons.org/licenses/by/4.0/. 
confirmed to be dose-duration-frequency dependent ${ }^{7}$. Higher cumulative dose and higher doses per treatment of cisplatin will result in greater kidney injury irreversibly ${ }^{8-10}$. Thus, it is necessary to establish novel effective drugs with no or less side effects for OS chemotherapy.

Dynasore is a cell-permeable small molecule that noncompetitively inhibits the GTPase activity of dynamin, which is a protein essential for cell adhesion, invasion, endocytosis, and phagocytosis ${ }^{11}$. Since identified by Macia in 2006, dynasore was widely utilized in the studies of endocytosis and macropinocytosis ${ }^{11,12}$. Recently, literatures have found that dynasore plays protective role in spinal injury ${ }^{13}$, Alzheimer disease ${ }^{14}$, and heart ischemia/ reperfusion injury ${ }^{15}$. In addition, dynasore suppresses the pseudopodia formation and cell invasion by destabilizing F-actin ${ }^{16,17}$. Moreover, in the latest study, dynasore exhibited anti-cancer potential via inhibiting cell proliferation and migration while induced apoptosis and mitochondrial dysfunction in lung cancer cell ${ }^{18,19}$. However, the anti-tumor effect of dynasore on OS has not yet been ascertained.

In the present study, we demonstrated that dynasore inhibited cell proliferation, migration, invasion, and tumorigenesis of OS without inducing cell apoptosis. By combining cisplatin and dynasore, we found that dynasore enhanced the anti-OS effect of cisplatin in vitro and in vivo. Furthermore, ERK-MAPK, PI3K-Akt, SAPK/JNK, p38 MAPK, and JAK2-STAT3 pathways were assessed to identify the underlying mechanisms of the antiproliferation effect of dynasore on OS.

\section{Materials and methods}

\section{Cell lines and cell culture}

All the OS cell lines (MNNG/HOS Cl\#5, MG-63, and U2-OS) were purchased from CBTCCCAS (Cell Cank, Type Culture Collection, Chinese Academy of Sciences) (Shanghai, China) and identified by STR analysis. All the three cell lines were cultured in DEM/F12 medium, supplemented with $10 \%$ fetal bovine serum (FBS), and incubated in $37^{\circ} \mathrm{C}, 5 \% \mathrm{CO}_{2}$ incubator.

\section{Reagents}

Dynasore was purchased from Target molecule Corp. (Targetmol, Shanghai, China) and dissolved with dimethylsulfoxide (DMSO, Sigma, USA) to a stock concentration of $100 \mathrm{mM}$. Cisplatin was bought from the National Institute for Food and Drug Control of China and dissolved with $0.9 \%$ normal saline solution (NS). To explore the inhibitory effects of dynasore and cisplatin, the cell viability of OS cells were detected in a serial concentration gradient $(0,10,20,50,100 \mu \mathrm{M}$ for dynasore, and $0,5,10,20,50 \mu \mathrm{M}$ for cisplatin) for $24 \mathrm{~h}, 48 \mathrm{~h}$, and $72 \mathrm{~h}$. Unless otherwise specified, the rest in vitro experiments were performed on four groups treated with
0.05\% DMSO (control group), $50 \mu \mathrm{M}$ dynasore, $5 \mu \mathrm{M}$ cisplatin, or $50 \mu \mathrm{M}$ dynasore combined with $5 \mu \mathrm{M}$ cisplatin (DC, combine group). To inhibit p38 MAPK signaling pathway, a specific inhibitor named SB239063 (MCE, China) was dissolved with DMSO and added $2 \mathrm{~h}$ before dynasore $(50 \mu \mathrm{M})$ treatment for a final concentration of $10 \mu \mathrm{M}$. IL6 $(50 \mathrm{ng} / \mathrm{ml}$, PeproTech, USA) was administrated $1 \mathrm{~h}$ before dynasore $(50 \mu \mathrm{M})$ to activate JAK2-STAT3 signaling.

\section{Cell proliferation assay}

The OS cell viabilities were detected by cell count kit-8 (CCK-8, Dojindo Molecular Technologies, Japan) according to the instruction of the manufacture. In brief, $5 \times 10^{3}$ OS cells were inoculated and cultured in a 96-well plate with $100 \mu \mathrm{l}$ culture medium. After treatment with different reagents, the culture medium were replaced with $100 \mu$ l CCK-8 detection solution $(90 \mu$ fresh medium mixed with $10 \mu \mathrm{l} \mathrm{CCK-8} \mathrm{solution).} \mathrm{After} \mathrm{incubation} \mathrm{in} \mathrm{cell}$ incubator $\left(37^{\circ} \mathrm{C}, 5 \% \mathrm{CO}_{2}\right)$ for $2 \mathrm{~h}$, the absorbance were valued via a microplate reader at $450 \mathrm{~nm}$ (Biotek, Winooski, VT, USA), and cell viability were calculated according to the instruction. To observe the proliferative cells intentionally, 5-ethynyl-20-deoxyuridine (EdU) incorporation assay was implemented using Cell-Light ${ }^{\mathrm{TM}}$ EdU Apollo ${ }^{\circledast} 567$ in vitro imaging kit (C10310-1, RiboBio, Guangzhou, China) according to the manufacture's instruction. The EdU assays were performed by three independent experiments, and cell counting was implemented by two investigators independently using the ImageJ software (National Institutes of Health, USA).

\section{Cloning formation assay}

After trypsinized into a single-cell suspension, OS cells (500 cells per well) were seeded and cultivated in a 6-well plate for $24 \mathrm{~h}$. Then, the cells were treated with DMSO, dynasore, and cisplatin with/without dynasore for another $48 \mathrm{~h}$. Culture medium was replaced into fresh DEM/F12 medium with $10 \%$ FBS after drugs treatment, and the medium was changed every 2 days. After 10 days of culture, the cells were fixed with $4 \%$ paraformaldehyde for $20 \mathrm{~min}$ and stained with $1 \%$ crystal violet for $30 \mathrm{~min}$. Clones were photographed by camera, and the clones with more than 50 cells were counted using microscope by two investigators. All the cloning formation assays were repeated three times.

\section{Wound healing assay}

$4 \times 10^{5}$ cells/well were inoculated into 6-well plate and maintained in $37^{\circ} \mathrm{C}, 5 \% \mathrm{CO}_{2}$ incubator for $24-48 \mathrm{~h}$ until cells reached $100 \%$ confluence. Then the cell monolayer was scratched to create a gap with $200 \mu$ pipette tip followed by PBS washing. Finally, the culture medium was changed into serum free DEM/F12 medium to suppress 
cell proliferation. The gaps were observed and photographed at $0 \mathrm{~h}$ and $24 \mathrm{~h}$ after scratching, and the area of scratches were calculated by ImageJ software.

\section{Cell migration and invasion assays}

The MNNG/HOS and MG-63 cells were treated with DMSO, dynasore, cisplatin, and dynasore combined with cisplatin for $48 \mathrm{~h}$. Then cells were trypsinized and $4-8 \times$ $10^{4}$ cells in $200 \mu \mathrm{l}$ serum free DEM/F12 were sucked into upper chamber of transwell $(8 \mu \mathrm{m}$ pore size, BD Biosciences, St Louis, USA) with or without pre-coated Matrigel (BD Biosciences, St Louis, USA) to evaluate cell invasion and migration capacity, respectively. $600 \mu \mathrm{l}$ culture medium containing $20 \%$ FBS was added into the lower chamber to stimulate cell travelling. After $36 \mathrm{~h}$ culture at $37^{\circ} \mathrm{C}, 5 \% \mathrm{CO}_{2}$ incubator, transwell chambers were fixed using $4 \%$ paraformaldehyde, and then stained with $1 \%$ crystal violet. Cells laid on upper surface of transwell membrane were wiped using a cotton swab, while cells traveled to the lower surface of membrane were photographed under a microscope. The average transmitted cells were counted by two investigators in three random fields $(100 \times)$.

\section{Flow cytometric analysis}

After treated with DMSO, dynasore, cisplatin, and dynasore combined with cisplatin for $48 \mathrm{~h}$, MNNG/HOS and MG-63 were harvested to perform flow cytometric analysis. For cell cycle distribution analysis, cells were washed by clod PBS and fixed with pre-cold 70\% ethanol overnight in $4{ }^{\circ} \mathrm{C}$. Then the cells were stained using Cell Cycle and Apoptosis Analysis Kit (Beyotime Biotehnology, China). In brief, cells were incubated in $37^{\circ} \mathrm{C}$ incubator with propidium iodide (PI) working solution for 30 min shielded from light. The cell cycle distribution was assessed via Flow Cytometry Caliber instrument (BD Biosciences, USA). Cell apoptosis assessment was performed by PE Annexin V Apoptosis Detection Kit I (BD Biosciences, USA) according to the instruction of the manufacture. After stained with 7-Amino-Actinomycin (7-AAD) and PE Annexin V for $15 \mathrm{~min}$ at room temperature, the cell apoptosis was analyzed by Flow cytometer. The 7-AAD negative and PE Annexin V positive cells were considered as early apoptotic cells, while those with double positive were determined as in late apoptosis or dead.

\section{Western blot analysis}

The total cell protein was extracted by RIPA lysis buffer containing cocktail protease inhibitor and phosphorylase inhibitor (Servicebio technology, China). Protein concentrations were determined by using BCA protein assay kit (Cwbiotech, China). Then, $20 \mu \mathrm{g}$ proteins were separated via $12 \%$ SDS-PAGE and transferred into PVDF membrane
$(0.22 \mu \mathrm{m}$, Millipore, Massachusetts, USA). After blocked by $0.5 \%$ defatted milk, membranes were incubated with diluted specific primary antibody and HRP conjugated secondary antibody, successively. Primary antibodies used in the present study include anti-GAPDH (1:10000, 10494-1-AP, Proteintech), anti-human antibody CDK4 (1:1000, ab108357, Abcam), anti-human antibody CCND1 (1:1000, ab40754, Abcam), anti-human antibody $p$-Rb (1:500, sc24585, Santa Cruz), anti-N-cadherin (1:1000, \#1311, Cell Signaling Technology), anti-MMP-2 (1:1000, 10373-2-AP, Proteintech), anti-MMP-9 (1:1000, 10375-2-AP, Proteintech), anti-JAK2 (phospho Y1007 + Y1008) (1:1000, ab32101, Abcam), anti-JAK2 (1:2000, ab108596, Abcam), anti-STAT3 (phospho Y705) (1:1000, ab76315, Abcam), anti-STAT3 (1:1000, ab68153, Abcam), anti-p38 (phospho T180) (1:1000, ab178867, Abcam), anti-p38 (1:1000, ab170099, Abcam), anti-Akt(phosphor S473) (1:1000, 66444-1-Ig, Proteintech), anti-Akt (1:1000, 10176-2-AP, Proteintech), anti-ERK1/2 (phospho T202 + T204)(1:1000, ab214362, Abcam), anti-ERK1/2 (1:5000, ab184699, Abcam), anti-SAPK/JNK (1:1000, \#9252, Cell Signaling Technology), anti-SAPK/JNK (phosphor Thr183/Tyr185) (1:1000, 81E11, Cell Signaling Technology). The secondary antibodies include HRP-conjugated affinipure goat antimouse IgG (1:5000, SA00001-1) and anti-rabbit IgG (1:5000, SA00001-2) both were purchased from Proteintech group, USA. The PVDF membranes were analyzed using ECL (Enhanced Chemiluminescence) Plus reagents and scanned with the BioSpectrum Imaging System (UVP, German).

\section{RNA isolation and quantitative real-time PCR}

The total RNA of MNNG/HOS and MG-63 was isolated using TRIzol $^{\circledR}$ Reagent (Life Technologies, USA) after treated with reagents described above. One $\mu \mathrm{g}$ of total RNA was reverse-transcribed using ReverTra Ace $^{\circledR}$ qPCR RT kit (TOYOBO, Japan) according to the manufacturer's instructions. Quantitative real-time PCR was performed in the CFX Connect ${ }^{\text {tm }}$ Real-Time PCR Detection System (Bio-Rad, USA) by using TB Green ${ }^{\mathrm{TM}}$ Premix $\mathrm{Ex} \mathrm{Taq}^{\mathrm{TM}}$ (TAKARA, Japan). The CT values were normalized to GAPDH expression, and mRNA expressions were calculated via $2^{-\Delta \Delta C t}$ method as described in previous research ${ }^{20}$. The primers used in present study are listed in Table 1.

\section{In vivo assay}

The in vivo experiment of this study was accomplished with the approval of the ethical committee of Tongji Medical College, Huazhong University of Science and Technology, and followed the institutional guideline and ethical standard. To establish subcutaneous transplanted model of OS, $3 \times 10^{6} \mathrm{MNNG} / \mathrm{HOS}$ cells were injected into the right axilla of each 5-week-old male nude mouse 
Table 1 Primers used in quantitative real-time PCR

\begin{tabular}{lll}
\hline Gene & Forward primer $\left(\mathbf{5}^{\prime} \boldsymbol{\rightarrow} \mathbf{3}^{\prime}\right)$ & Reverse primer $\left(\mathbf{5}^{\prime} \boldsymbol{\rightarrow} \mathbf{3}^{\prime}\right)$ \\
\hline CDK4 & TCAGCACAGTTCGTGAGGTG & GTCCATCAGCCGGACAACAT \\
CCND1 & GCTGCGAAGTGGAAACCATC & CCTCCTTCTGCACACATTTGAA \\
STAT3 & CAGCAGCTTGACACACGGTA & AAACACCAAAGTGGCATGTGA \\
GAPDH & AATCCCATCACCATCTTCCAG & GAGCCCCAGCCTTCTCCAT \\
\hline
\end{tabular}

(BALB/c-nu, Beijing HFK Bioscience, China). The xenografts were measured by micrometer caliper, and the tumor volume was calculated based on length (a) and the width (b) by the following formula: tumor volume $=\mathrm{ab}^{2}$. When xenografts volume reached $80-100 \mathrm{~mm}^{3}$, nude mice were divided into four groups randomly and received the following interventions every day: (1) in control group, mice were peritumoral subcutaneously and intraperitoneally injected with $100 \mu$ NS respectively; (2) in Dynasore group, $100 \mu \mathrm{l}$ NS with or without dynasore $(10 \mathrm{mg} / \mathrm{kg})$ were peritumoral subcutaneous and intraperitoneal injected, respectively; (3) in Cisplatin group, $100 \mu \mathrm{l}$ NS without or with cisplatin $(2 \mathrm{mg} / \mathrm{kg})$ were peritumoral subcutaneous and intraperitoneal injected, respectively; (4) in combination group(DC), $100 \mu \mathrm{l}$ NS containing dynasore $(10 \mathrm{mg} / \mathrm{kg})$ and $100 \mu \mathrm{l} \mathrm{NS}$ supplemented with cisplatin $(2 \mathrm{mg} / \mathrm{kg})$ were injected peritumoral subcutaneously and intraperitoneally, respectively. To explore the role of p38 MAPK pathway in dynasore induced anti-proliferation effect of OS in vivo, another xenograft mouse model was performed as described above, and the cisplatin $(2 \mathrm{mg} / \mathrm{kg})$ treatment was replaced with $10 \mathrm{mg} / \mathrm{kg} \mathrm{SB} 239063^{21}$ (intraperitoneal injection). All the mice were sacrificed after intervened for one week, and xenografts, livers and kidneys were resected carefully and fixed in $4 \%$ paraformaldehyde for H\&E staining and immunohistochemistry assay.

\section{Histopathology and immunohistochemistry}

The samples were embedded in paraffin and sectioned to $4 \mu \mathrm{m}$ thickness. The sample sections (tumors, livers, and kidneys) were dewaxed and stained with Hematoxylin and Eosin Staining Kit (Beyotime Biotechnology, China) according to the manufacture's instruction. Additionally, to explore the protein expression in OS xenografts, the tumor sections were used to perform immunohistochemistry with Ki67 (1:200, ab16667, Abcam), STAT3 (1:100, ab68153, Abcam) or $p$-STAT3 (1:100, ab76315, Abcam) primary antibodies and a biotin-conjugated affinipure goat anti-rabbit IgG (1:500, SA00004-2, Proteintech). For negative controls, immunohistochemistry was carried out in the absence of primary antibodies.

\section{Immunofluorescence assay}

$2-4 \times 10^{4} /$ well MNNG/HOS and MG-63 cells were seeded on circle cover glass $(\phi=20 \mathrm{~mm})$ in 12-well plate, and treated with $0.05 \%$ DMSO or $50 \mu \mathrm{M}$ dynasore for $48 \mathrm{~h}$. Cells were then fixed with $4 \%$ paraformaldehyde at $4{ }^{\circ} \mathrm{C}$ for $15 \mathrm{~min}$, and permeabilized with $1 \%$ triton $\mathrm{X}-100$ for $20 \mathrm{~min}$. After $1 \mathrm{~h}$ blocking in PBS containing with $10 \%$ FBS, cells were incubated in STAT3 (1:500, ab68153, Abcam) or p-STAT3 (1:500, ab76315, Abcam) primary antibodies at $4{ }^{\circ} \mathrm{C}$ overnight. Then, the cells were washed with PBST for three times (5 min each time), and incubated with Dylight 488 goat anti-rabbit IgG secondary antibodies (1:500, Abbkine, USA) for $2 \mathrm{~h}$ at room temperature. Cell nucleus was stained via Hoechst 33342 (Beyotime Biotechnology, China) for $5 \mathrm{~min}$ at room temperature.

\section{Statistical analysis}

Results of the present study were expressed as mean \pm SEM for at least three independent experiments and analyzed by using SPSS 21.0 software (IBM, Chicago, IL, USA) and GraphPad Prism 6. Two-tailed student's $t$-test was used to examine significant difference between any two groups, while one-way ANOVA was performed to assess the statistical significance between three or more groups. $\quad P<0.05$ was considered as statistically significant.

\section{Results}

\section{Dynasore inhibits cell proliferation of OS in vitro}

Human OS cell lines (MNNG/HOS, MG-63, and U2OS) were treated with increasing concentrations of dynasore or cisplatin, and then the cell viability was assessed by CCK- 8 kit at 24, 48, and $72 \mathrm{~h}$. As shown in Fig. 1a, b, the cell abilities of MNNG/HOS, MG-63, and U2-OS were suppressed in a time- and concentrationdependent manner either treated with dynasore or cisplatin. To evaluate the synergistic antitumor effect of dynasore and cisplatin, cells were exposed to dynasore $(50 \mu \mathrm{M})$ or/and cisplatin $(5 \mu \mathrm{M})$ for $48 \mathrm{~h}$. As expected, cell viabilities were significantly decreased in dynasore group and cisplatin group, while those in dynasore and cisplatin combination group (DC group) were further suppressed (Fig. 1c). Besides, the CDIs (Coefficients of Drug Interaction) of $50 \mu \mathrm{M}$ dynasore and $5 \mu \mathrm{M}$ cisplatin in MNNG/ HOS, MG-63, and U2-OS cells were reached up to $0.80 \pm$ $0.03,0.58 \pm 0.05$, and $0.54 \pm 0.05$, which means dynasore promoted the antitumor capacity of cisplatin. Then, the effects of dynasore and cisplatin alone or in combination were analyzed via observing cell morphology. Unlike apoptosis-inducing feature of cisplatin, dynasore exhibited a significant inhibitory effect on cell density. In DC group, both anti-proliferation and apoptosis-inducing effects were observed (Supplemental Figs. 1-3). 

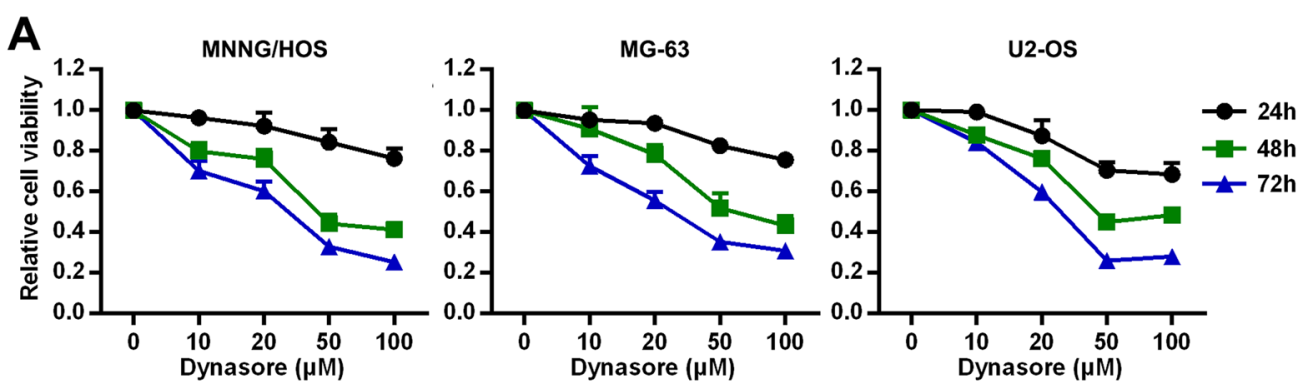

B
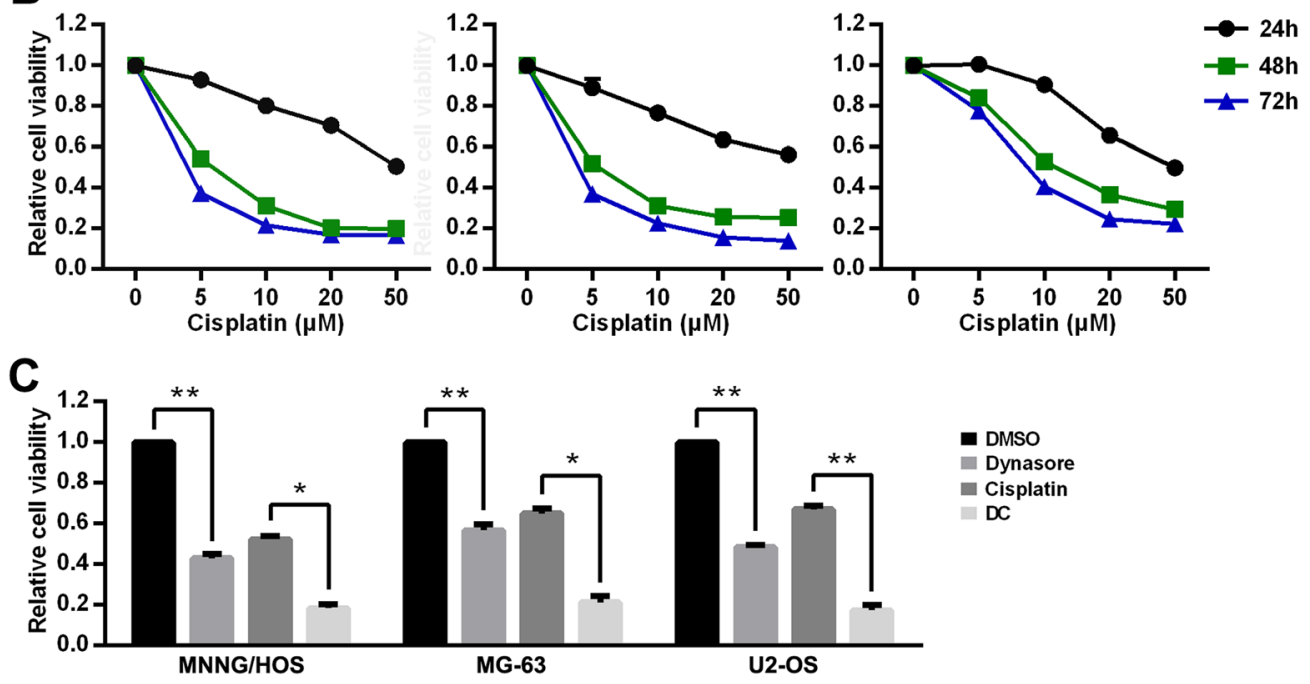

Fig. 1 Inhibitory effect of dynasore and cisplatin on the cell viability of OS cells (MNNG/HOS, MG-63, and U2-OS cell lines). a Cell viabilities of OS cells after treated with different concentrations of dynasore for 24,48 , and $72 \mathrm{~h}$. b Cell viabilities of OS cells after treated with different concentrations of cisplatin for 24,48 , and $72 \mathrm{~h}$. c Cell viabilities of OS cells after treated with $50 \mu \mathrm{M}$ dynasore and/or $5 \mu \mathrm{M}$ cisplatin for $48 \mathrm{~h}$. ${ }^{*} p<0.05$ and ${ }^{* *} p<0.01$, vs. DMSO group. DC, $50 \mu \mathrm{M}$ dynasore combined with $5 \mu \mathrm{M}$ cisplatin

To further estimate the anti-proliferation effect of dynasore on OS cells, EdU staining was performed in MNNG/HOS and MG-63 cells. As depicted in Fig. 2a-d, both dynasore and cisplatin treatment significantly decreased the EdU positive rate in OS cells $(17.80 \pm 1.56 \%$ in dynasore group and $3.46 \pm 0.45 \%$ in cisplatin group vs. $50.51 \pm 1.42 \%$ in control group in MNNG/HOS, $p<0.01 ; 19.27 \pm 0.95 \%$ in dynasore group and $6.75 \pm 1.14 \%$ in cisplatin group vs. $33.37 \pm 0.85 \%$ in control group in MG-63, $p<0.01$ ). Consistent with our previous results, the EdU positive rate of dynasore and cisplatin combination group (MNNG/HOS: $0.77 \pm$ $0.08 \%, p<0.01$; MG-63: $1.59 \pm 0.14 \%, p<0.01)$ were significantly lower than cisplatin group. In addition, cloning formation assay demonstrated similar results (Fig. 2e, f). However, with the shadow of the powerful anti-colony formation effect of cisplatin in MG-63, dynasore decreased the relative colony formation rate with no statistical evidence $(0 \pm 0 \%$ vs. $1 \pm 0.71 \%, p=$ $0.158)$.
Thus, these results indicated that dynasore significantly suppressed viability, proliferation, and colony formation of OS cells, and has synergy effect with cisplatin.

\section{Dynasore induces G0/G1 arrest but not cell apoptosis of OS cells}

The cell cycle distribution and apoptosis of MNNG/ HOS and MG-63 were evaluated using flow cytometry after treatment with dynasore and cisplatin alone or in combination. As revealed in Fig. 3a, b, dynasore exposures led to accumulation in G0/G1 phase both in MNNG/HOS $(56.04 \pm 1.08 \%$ vs. $42.36 \pm 0.25 \%, p<0.01)$ and MG-63 cells $(70.30 \pm 0.50 \%$ vs. $60.74 \pm 0.11 \%, p<0.01)$, while cisplatin accumulated cells in S phase $(93.62 \pm 0.38 \%$ vs. $39.50 \pm 0.44 \%$ in MNNG/HOS; $84.71 \pm 2.60 \%$ vs. $26.63 \pm$ $1.67 \%$ in MG-63, $p<0.01$ ). Surprisingly, compared with cisplatin group, dynasore combined with cisplatin significantly increased the population of OS cells in G0/G1 phase $(20.39 \pm 0.21 \%$ vs. $4.09 \pm 0.05 \%$ in MNNG/HOS and $9.87 \pm 1.27 \%$ vs. $1.52 \pm 1.92 \%$ in MG-63). To further 


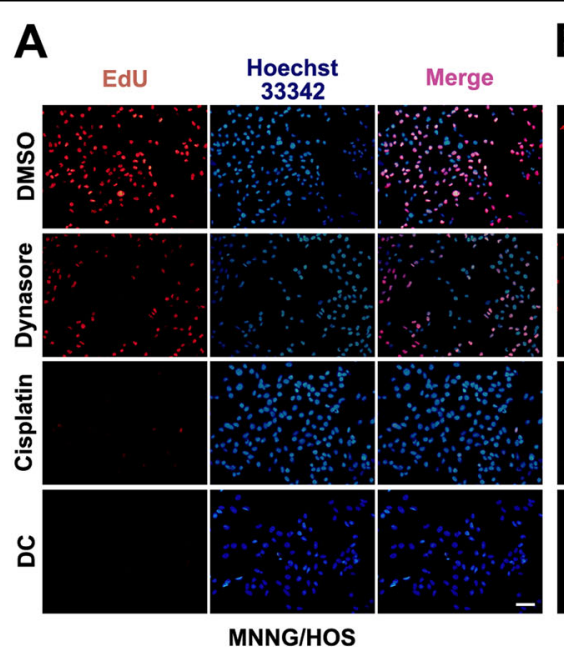

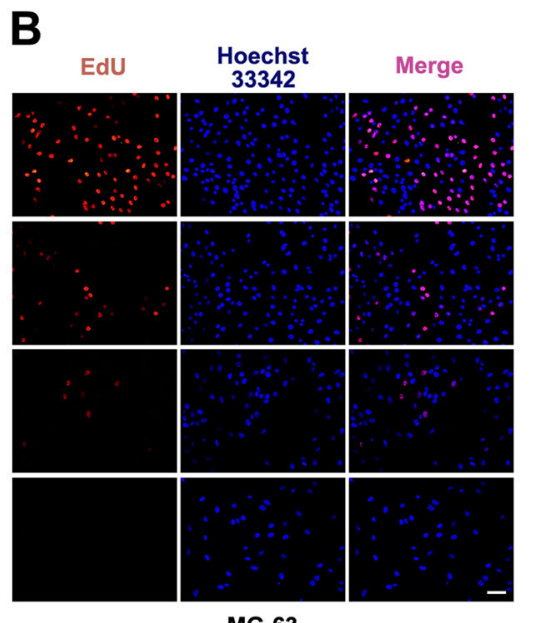

MG-63
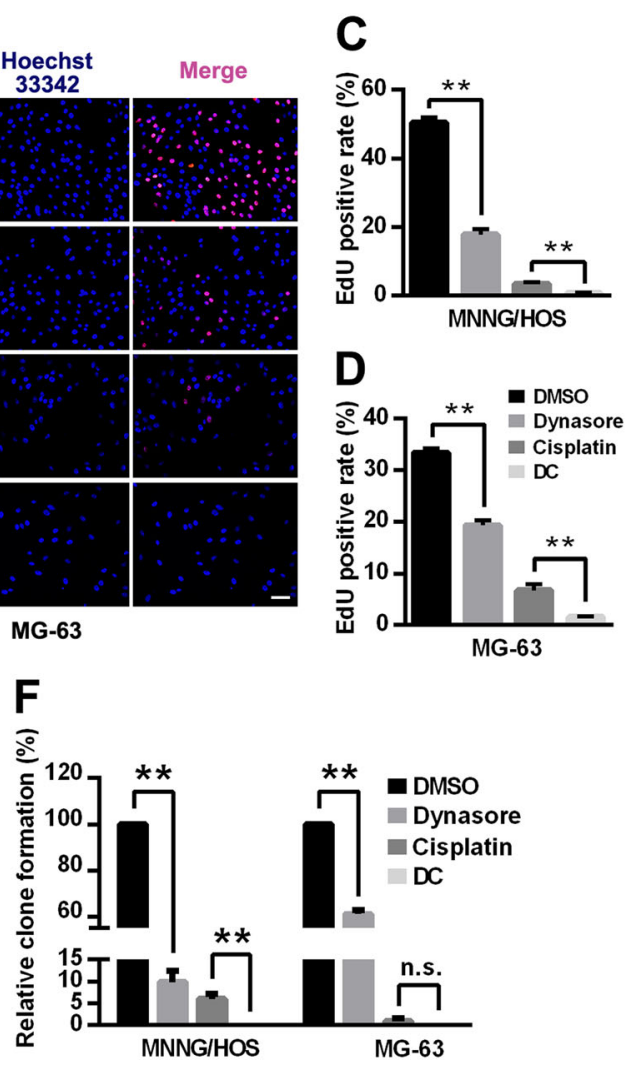

Fig. 2 Inhibitory effect of dynasore and/or cisplatin on cell proliferation of OS cells. Cell proliferation was detected by EdU staining in MNNG/ HOS (a) and MG-63 (b). EdU positive rates of MNNG/HOS (c) and MG-63 (d) were shown as histograms. e Cloning formation of MNNG/HOS and MG63 after treated with $50 \mu \mathrm{M}$ dynasore and/or $5 \mu \mathrm{M}$ cisplatin for $48 \mathrm{~h}$. $\mathbf{f}$ Histograms of relative cloning formation of OS cells. ${ }^{* *} p<0.01$ vs. DMSO group. n.s., not significant. Scale bar: $50 \mu \mathrm{m}$

elucidate the mechanisms, the transcription and expression of proteins essential for cell cycle G1/S transition were analyzed via real-time PCR and western blot, respectively. As shown in Fig. 3c-f, dynasore downregulated both mRNA and protein levels of CCND1 and CDK4. Moreover, the phosphorylation of $\mathrm{Rb}$, a protein that sequesters E2F to suppress transcription activation, was significantly inhibited by dynasore in both MNNG/ HOS and MG-63 cells. Compared with cisplatin treatment, the expression of $p$-Rb, CCND1, and CDK4 were also down-regulated when dynasore was added.

Furthermore, cell apoptosis was detected in MNNG/ HOS and MG-63 (Fig. 3g, h). Astonishingly, although dynasore treatment for $48 \mathrm{~h}$ mildly increased apoptosis of OS cells, statistically significant differences were found neither between dynasore group and control group $(p=$ 0.390 and $p=0.116$ ) nor between DC group and cisplatin group ( $p=0.386$ and $p=0.121$ ).

Therefore, these results suggests that dynasore induces G0/G1 arrest through inhibiting the expression of $p-\mathrm{Rb}$, CCND1, and CDK4, while not affects apoptosis of OS cells in vitro.

\section{Dynasore suppresses OS cell migration and invasion}

The capacity of migration and invasion play a crucial role in OS distant metastasis and local invasion. As shown in Fig. 4a-d, the wound healing assay revealed that dynasore significantly delayed the lessening of the scratch area in both OS cells, and migration rates were significantly decreased in DC group when compared with cisplatin group. Consistent with wound healing assay, the transwell migration (Fig. 4e-g) and invasion assays (Fig. $4 \mathrm{~h}-\mathrm{j}$ ) exerted the same pattern of effects of dynasore and cisplatin, indicating that dynasore exposure inhibited cell migration and invasion capacity and enhanced the inhibitory effect of cisplatin in OS cells. Furthermore, we examined cell migration an invasion relevant proteins (N-cadherin, MMP-2, and MMP-9) after treatment with dynasore and cisplatin alone or in combination. As exhibited in Fig. $4 \mathrm{k}-\mathrm{m}$, both dynasore and cisplatin alone suppressed the expression of MMP-2 significantly in MNNG/HOS and MG-63 cells, and the effects are more prominent in combination group. However, dynasore combined with cisplatin decreased $\mathrm{N}$-cadherin expression when compared with cisplatin in both cells, while no effects on $\mathrm{N}$ cadherin were observed when dynasore was used alone. 

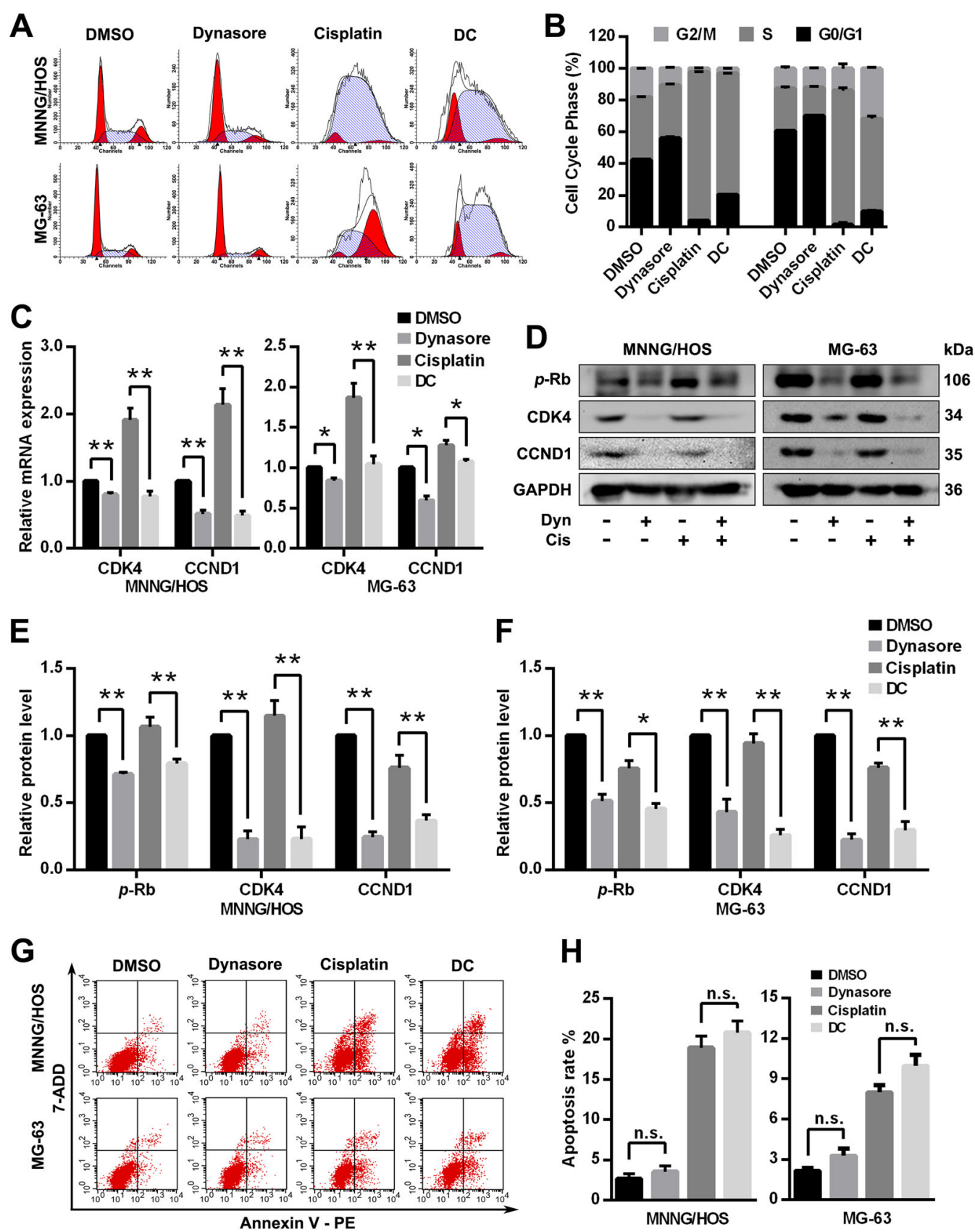

Fig. 3 Dynasore induces G0/G1 cell cycle arrest but not cell apoptosis of OS cells. a The representative data of PI staining and folw cytometric analysis of OS cells treated with dynasore and/or cisplatin. b Histograms of cell cycle distribution of MNNG/HOS (left) and MG-63 (right) show that dynasore significantly increases the percentages of cells in G0/G1 phase. $\mathbf{c}$ The relative mRNA expression of CDK4 and CCND1 in OS cells. $\mathbf{d}$ Representative western blot analysis for $p$-Rb, CDK4, and CCND1 in OS cells. Relative protein levels of $p-R b, C D K 4$, and CCND1 in MNNG/HOS (e) and MG-63 (f) cells are shown as histograms. $\mathbf{g}$ The representative data of cell apoptosis. $\mathbf{h}$ Histograms of cell apoptosis rates of OS cells. ${ }^{*} p<0.05$ and ${ }^{* *} p<0.01$ vs. DMSO group. n.s., not significant

Dynasore inhibits OS tumorigenesis without inducing nephrotoxicity and hepatotoxicity in vivo

In order to determine the potential value of dynasore in OS treatment, a xenograft mouse model was established and the volumes of tumors were measured every day. The administration of dynasore resulted in significantly decreased in tumor volume (Fig. 5a-c, $p<0.05$ ). Furthermore, DC group gained the greatest suppression effect in OS growth (Fig. 5a-c, $p<0.05$ ), while the mean tumor volume in cisplatin group were in between 


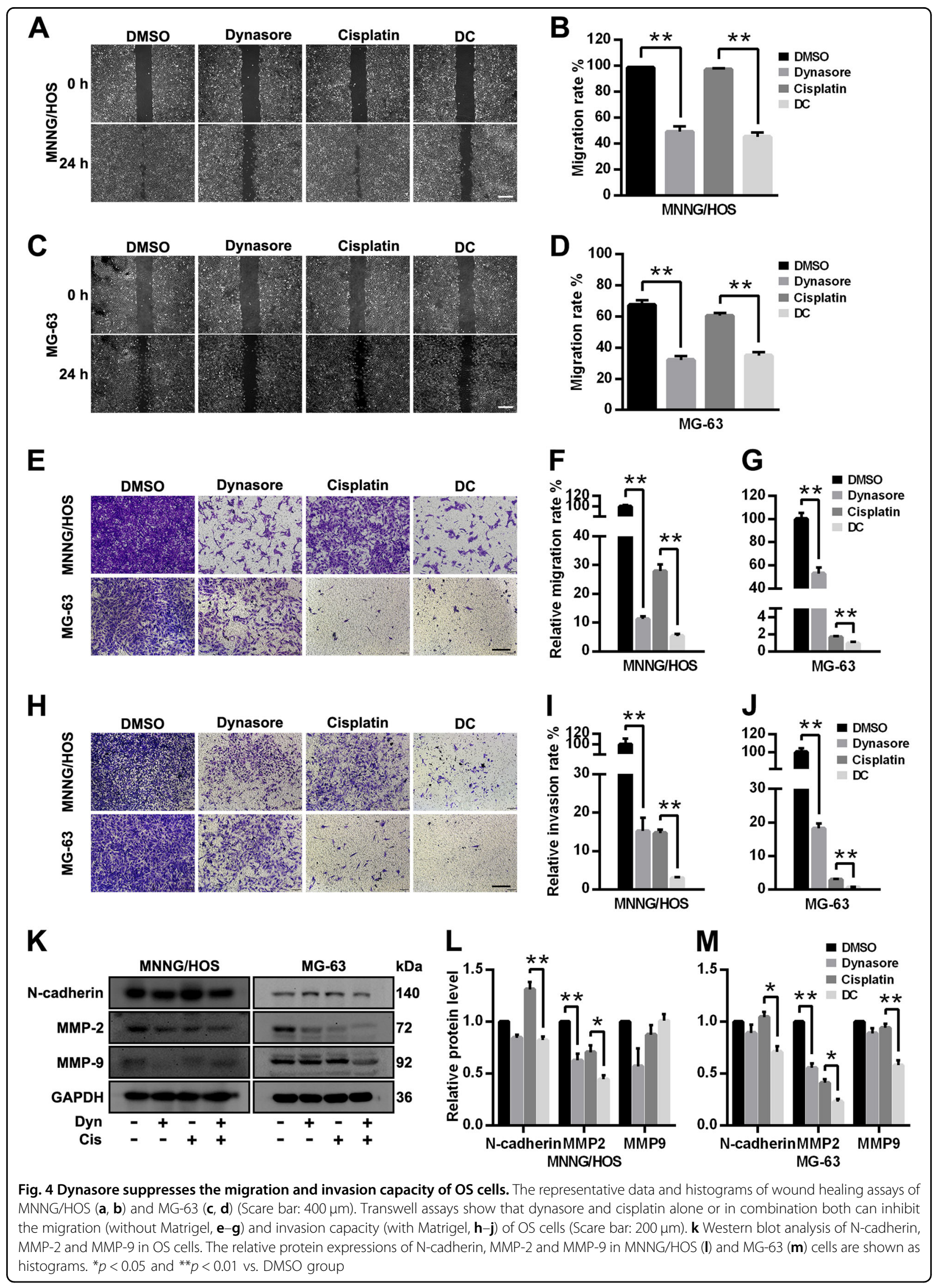




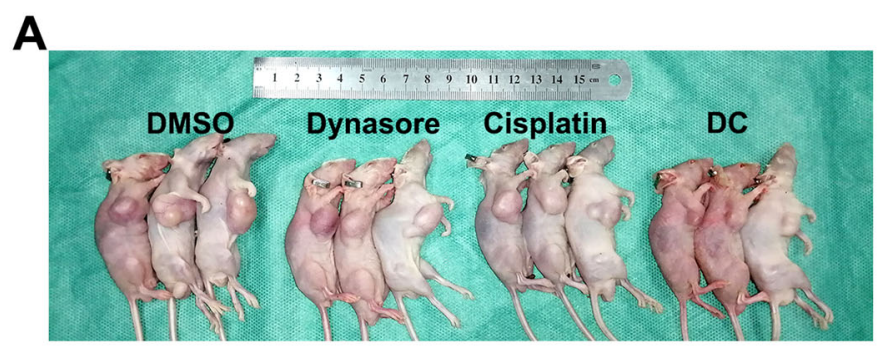

B

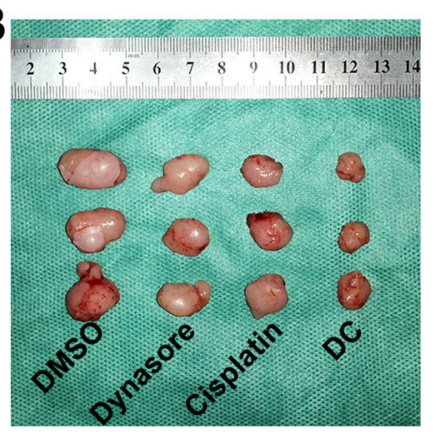

$\mathbf{F}$

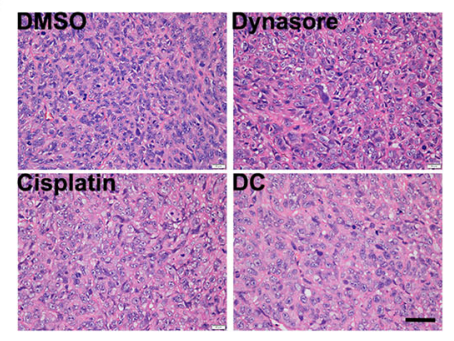

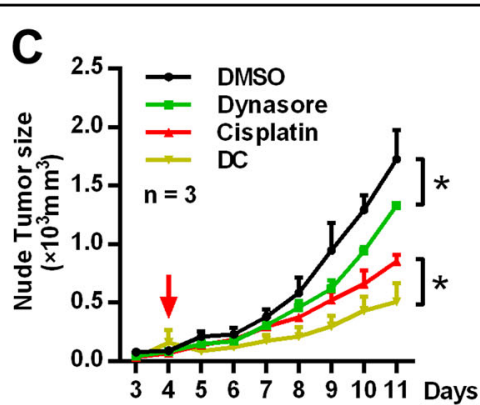

$E$
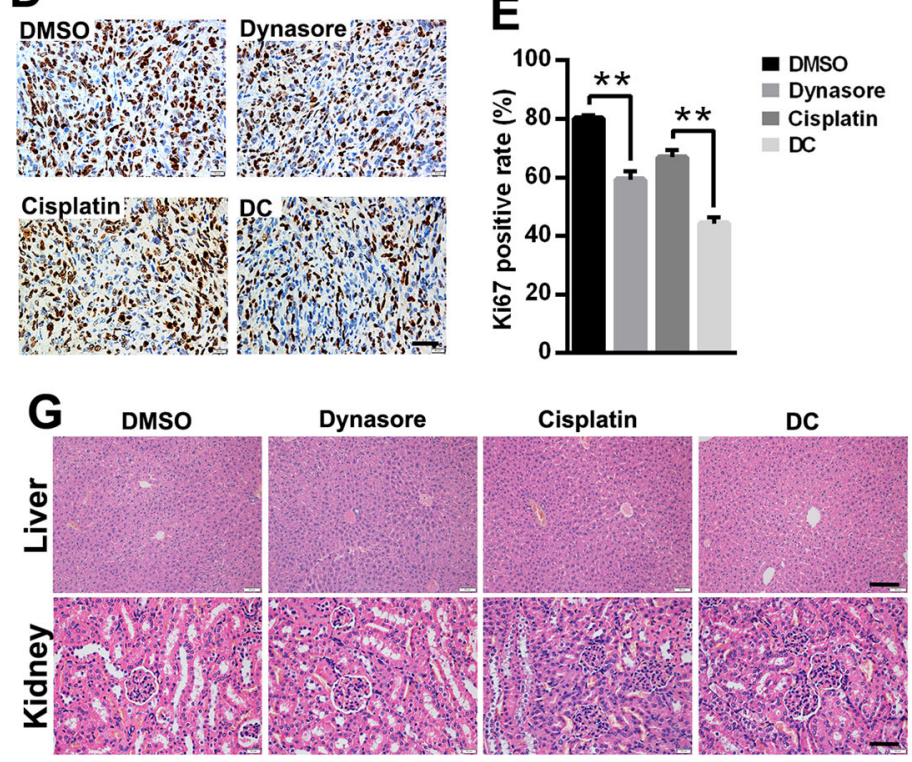

Fig. 5 Effects of dynasore and cisplatin in OS xenograft mouse model. $\mathbf{a}, \mathbf{b}$ The representative mice and tumors of the xenograft mouse modes in DMSO, dynasore $(10 \mathrm{mg} / \mathrm{kg})$, cisplatin $(2 \mathrm{mg} / \mathrm{kg})$ and combination-treated groups. c Tumor volumes were measured every day since day 3 after model establishment (day 0), and drugs administration were initiated at day 4 (red arrow). $\mathbf{d}$, e Xenograft tumor tissues were subjected to IHC staining by using Ki67 antibody (Scare bar: $40 \mu \mathrm{m}$ ). Tumor samples (f) (Scare bar: $40 \mu \mathrm{m}$ ), liver (Scare bar: $100 \mu \mathrm{m})$ and kidney (Scare bar: $40 \mu \mathrm{m})$ samples (g) of four xenograft mice groups were under H\&E staining. ${ }^{*} p<0.05$ and ${ }^{* *} p<0.01$ vs. DMSO group

dynasore group and DC group. As revealed in in vitro assays, dynasore highlights an anti-proliferation effect when treated alone or combined with cisplatin in OS cells. Therefore, the expressions of Ki67 were detected in xenografts by using IHC (Fig. 5d, e). Dynasore and cisplatin alone both significantly reduced Ki67 expression in vivo. In addition, the average Ki67 positive rate was further decreased when dynasore and cisplatin were administrated together. As shown in Fig. 5f, the OS cell densities in xenografts were much lower when treated with dynasore, while cisplatin alone caused mainly cell death and fatty degeneration. Besides, tumors in DC group had features of dynasore and cisplatin groups, and achieved a better effect of growth suppression in vivo.

Furthermore, the histomorphology of liver and kidneys of xenografts mice was analysis by H\&E staining (Fig. 5g). Surprisingly, no obvious evidences showed that dynasore induced nephrotoxicity or hepatotoxicity in the present study. However, in cisplatin treated mice, edematous glomeruli and swollen and degenerated renal tubular epithelial cells were observed.

Taken together, dynasore exerted anti-tumorigenesis effect mainly by inducing proliferation repression on OS without causing or nephrotoxicity or hepatotoxicity.

\section{P38 MAPK signaling pathway is involved in dynasore induced anti-osteosarcoma effects}

Next, western blot was conducted to further explore the signaling pathways involved in dynasore induced antiproliferation effect. Dynasore significantly increased the phosphorylation levels of p38 (Fig. 6a-c). Moreover, as expected, $p$-p38 level was up-regulated in DC group compared with cisplatin group. These results indicated that p38 MAPK signaling pathway was involved in dynasore induce anti-osteosarcoma effects. However, when SB239063, a specific inhibitor of p38 MAPK, was 

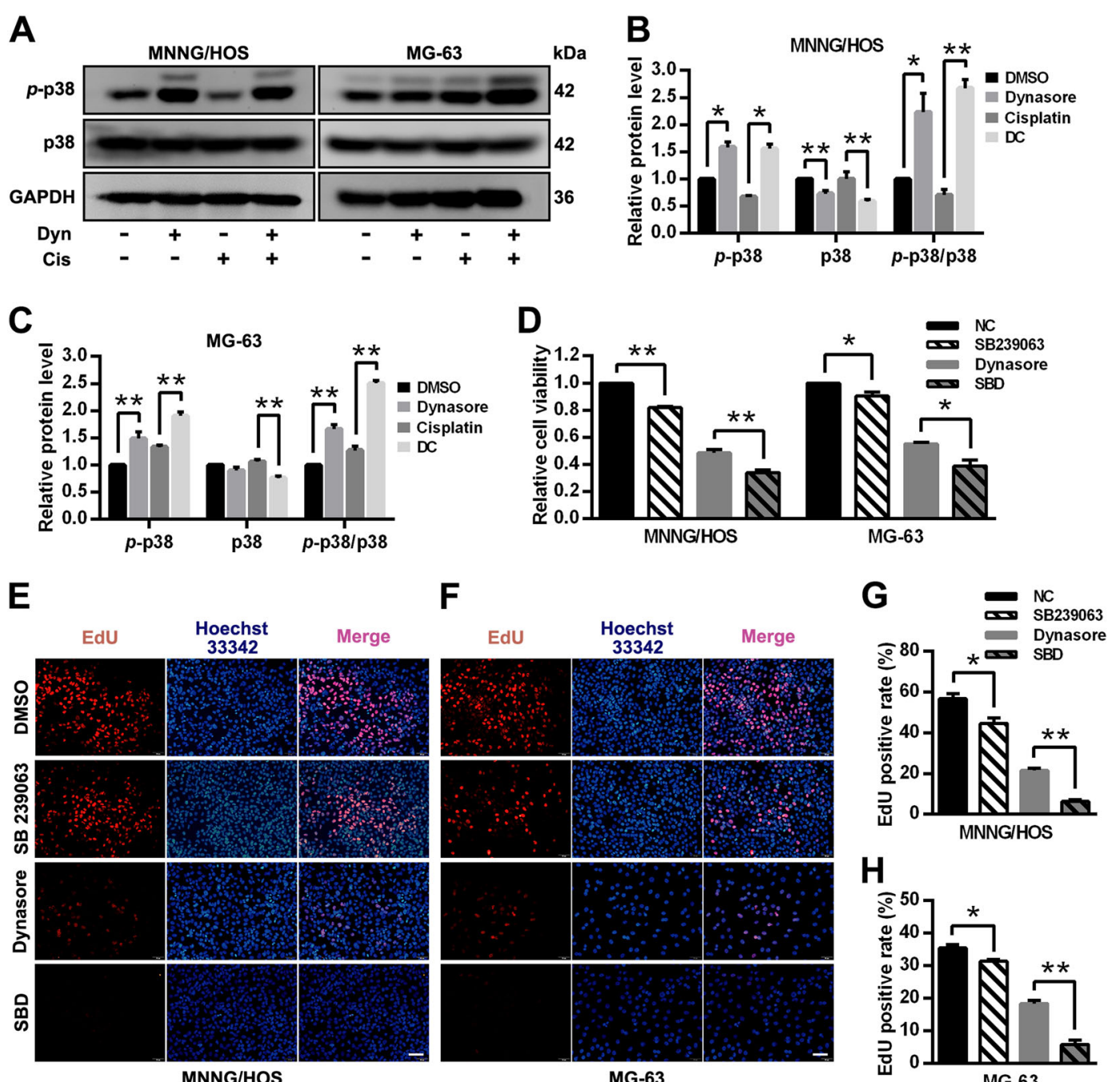

MNNG/HOS

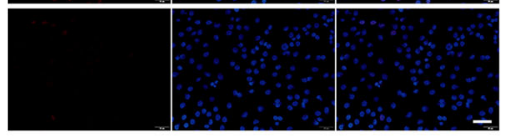

MG-63
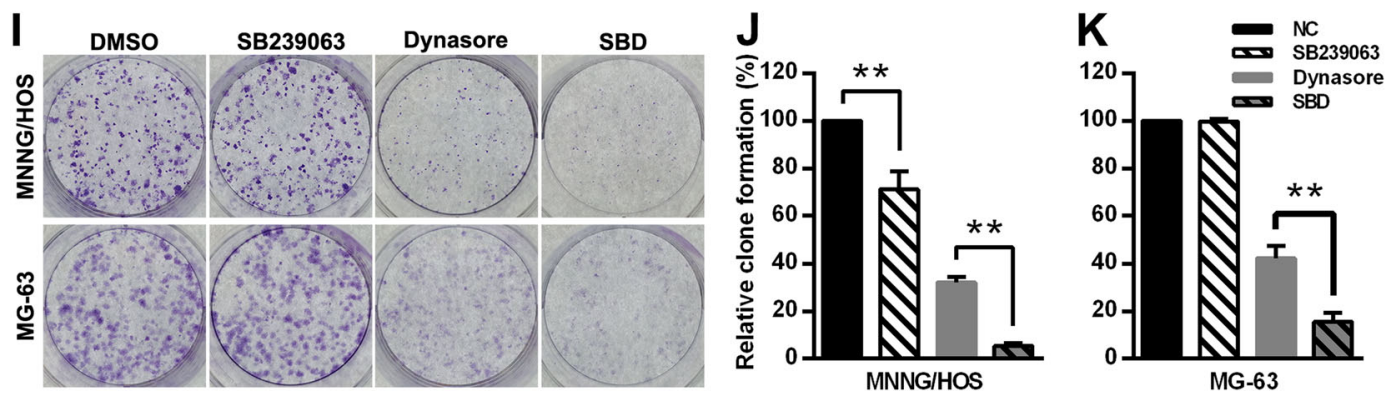

Fig. 6 P38 MAPK signaling pathway serves as a negative regulator in dynasore induced proliferative inhibition. a Western blot analysis of $p$ p38 and p38 of OS cells after treated with dynasore and/or cisplatin. The relative protein expression of p-p38 and p38 in MNNG/HOS (b) and MG-63 (c) were shown as histogram. d The cell viability of OS cells after treated with SB239063 (10 $\mu \mathrm{M})$ followed by dynasore exposure. After suppression of p38 MAPK pathway by SB239063, cell proliferations were analyzed by EdU staining (MNNG/HOS $(\mathbf{e}, \mathbf{g})$ and MG-63 cells (f, $\mathbf{h})$ ) and cloning formation assay (I-K). ${ }^{*} p<0.05$ and ${ }^{* *} p<0.01$ vs. DMSO group. SBD, co-treated with $50 \mu \mathrm{M}$ dynasore and $10 \mu \mathrm{M}$ SB239063 as described in "Materials and methods" section. Scale bar: $50 \mu \mathrm{m}$

applied to inhibit the activation of this pathway, dynasore enhanced its anti-proliferation effect dramatically. The cell ability suppression capacities of dynasore in MNNG/ HOS and MG-63 were more prominent after pre-treated with SB239063 (Fig. 6d). EdU staining and colony formation assay demonstrated the same pattern of effects of dynasore when SB239063 was used (Fig. 6e-k). In in vivo assay, the tumor growth was not affected by SB239063. 

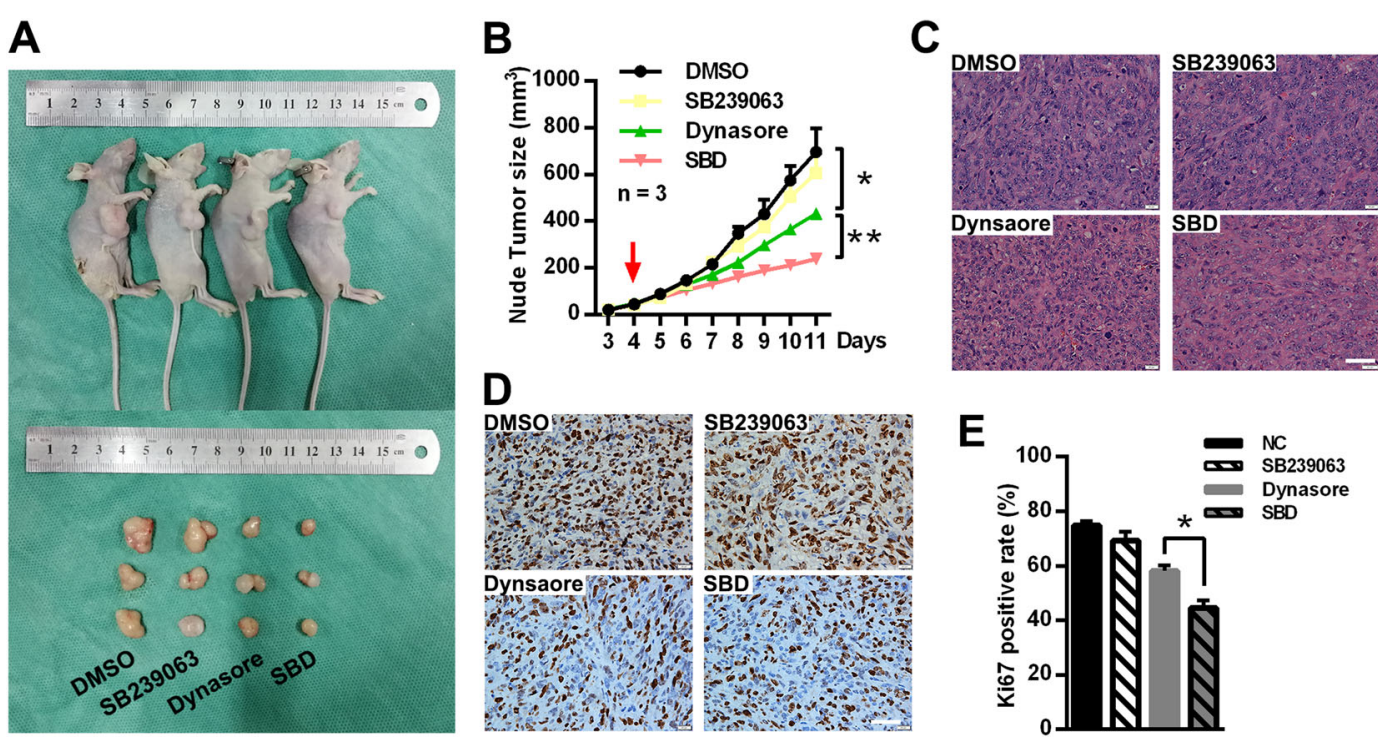

Fig. 7 Effects of p38 MAPK pathway inhibitor SB239063 in dynasore induced anti-OS in vivo. a The representative mouse and tumors of the xenograft mouse modes in DMSO, SB239063 $(10 \mathrm{mg} / \mathrm{kg})$, dynasore $(10 \mathrm{mg} / \mathrm{kg})$ and combination-treated groups. b Tumor volumes were measured every day since day 3 after model establishment (day 0), and drugs administration were initiated at day 4 (red arrow). c Tumor samples of four xenograft mice groups were under H\&E staining (Scare bar: $40 \mu \mathrm{m}$ ). d, e Xenograft tumor tissues were subjected to IHC staining by using Ki67 antibody (Scare bar: $40 \mu \mathrm{m}) .{ }^{*} p<0.05$ and ${ }^{* *} p<0.01$ vs. DMSO group

However, the tumor volumes in the group treated with dynasore and SB239063 were significantly smaller than those in dynasore group (Fig. 7a, b). By H\&E staining, we found that the cell density in xenografts of SB239063 and dynasore combination group (SBD group) was much sparser than that in dynasore group (Fig. 7c). In addition, the average ki67 positive rate in SBD group was significantly lower than that in dynasore group (44.62 \pm $2.73 \%$ vs. $58.23 \pm 3.33 \%, p<0.05$, Fig. $7 d$, e). Taken together, p38 MAPK pathway might serves as a negative regulator in dynasore induced proliferation inhibition. However, the phosphorylation of ERK1/2, Akt and JNK did not have significant differences between control and dynasore treated group (Supplemental Fig. 4), indicating that MAPK ERK1/2, PI3K-Akt, and SAPK/JNK pathways might not involve in repression of OS proliferation induced by dynasore.

\section{Dynasore inhibits cell proliferation via STAT3 pathway}

In the previous results, we found p38 MAPK, which acted as a negative regulator, was involved in the effects of dynasore on OS. Here, we further studied the role of JAK2/SAT3 pathway in dynasore-induced inhibition of OS proliferation. The phosphorylations of JAK2 were significantly suppressed by dynasore in both MNNG/HOS and MG-63 cells (Fig. 8a-c). Surprisingly, the expression of STAT3 and $p$-STAT3 were both significantly downregulated in dynasore group, and the $p$-STAT3 levels were indeed repressed by dynasore when standardized to total
STAT3 expression (Fig. 8a-c). Moreover, the expressions of these proteins were reduced in DC group when compared with cisplatin group. Furthermore, by using realtime PCR, no significant difference of mRNA expression of STAT3 was found in dynasore group and control group. However, up-regulated STAT3 transcription levels, which was reversed by dynasore in DC group, was detected after cisplatin intervention (Fig. 8d). Consistent with in vitro detection, the $p$-STAT3 and STAT3 expression were decreased in xenografts OS tumors exposed to dynasore (Fig. 8e). To intuitively observe the effects of dynasore on subcellar location of STAT3 and $p$ STAT3, immunofluorescence experiments were performed. As exhibited in Fig. 8f, g, the fluorescence intensities of STAT3 and $p$-STAT3 were decreased both in nucleus and cytoplasm in dynasore treated group. In order to investigate the relationship between cell cycle arrest and JAK2/STAT3 pathway repression, the expressions of CCDN1, CDK4 and phosphorylation of JAK2 and STAT3 were evaluated at $0,3,6,12,24,48 \mathrm{~h}$ after dynasore treatment. As expected (Fig. 9a), the CCND1, CDK4, $p$-JAK2, and $p$-STAT3 levels started decreasing at $24 \mathrm{~h}$ and were dramatically reduced at $48 \mathrm{~h}$, simultaneously.

Furthermore, after activated by inflammatory cytokine Interleukin-6 (IL-6), a cytokine that was identified as a well-established STAT3 signaling pathway activator ${ }^{22}$, the effects of dynasore on cell viability and proliferation of OS cells were determined by CCK- 8 assay and EdU staining. The inhibitory effect of dynasore on cell viability (Fig. 9b) 

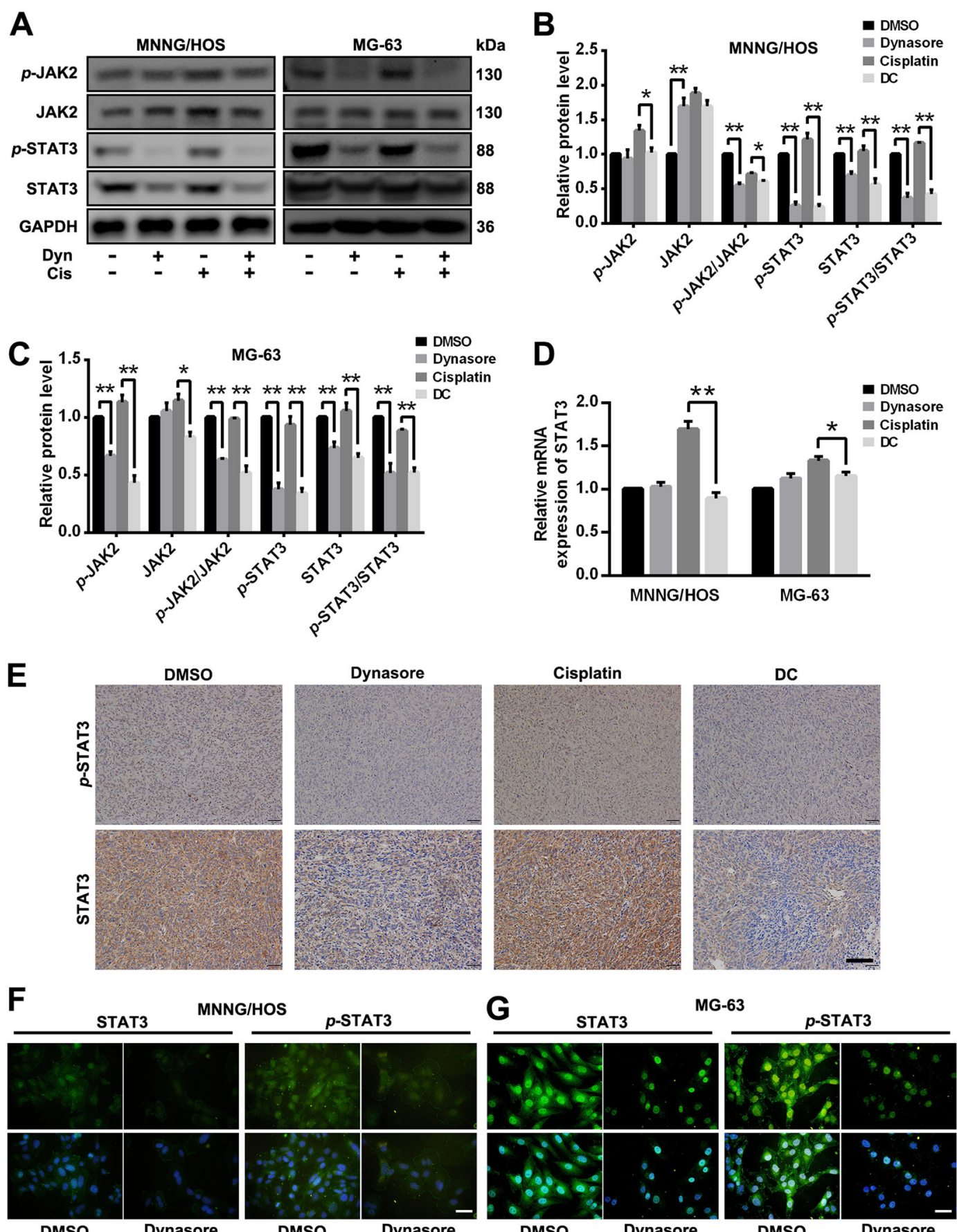

Fig. 8 Dynasore inhibit the activation of STAT3 signaling pathway. a Western blot analysis of p-JAK2, JAK2, p-STAT3 and STAT3 of OS cells after treated with dynasore and/or cisplatin. The relative protein expression of $p$-JAK2, JAK2, p-STAT3, and STAT3 in MNNG/HOS (b) and MG-63 (c) were shown as histogram. $\mathbf{d}$ The mRNA expression of STAT3 in MNNG/HOS and MG-63 cells after dynasore and/or cisplatin exposure for $48 \mathrm{~h}$. e The $p$ STAT3 and STAT3 expression in xenograft tumor tissues were detected by using IHC staining (Scale bar: $100 \mu \mathrm{m}$ ). The $p$-STAT3 and STAT3 expression were detected by using immunohistochemistry assay in MNNG/HOS (f) and MG-63 cells (g) (Scale bar: $20 \mu \mathrm{m}) .{ }^{*} p<0.05$ and ${ }^{* *} p<0.01$ vs. DMSO group

and proliferation (Fig. 9c-f) was almost abrogated by IL-6 stimuli, indicating that dynasore inhibited OS cell proliferation via deactivating STAT3 pathway.

\section{Discussion}

The prognosis of patients with OS has been improved with the implementation of chemotherapy in the $1970 \mathrm{~s}^{2}$. 

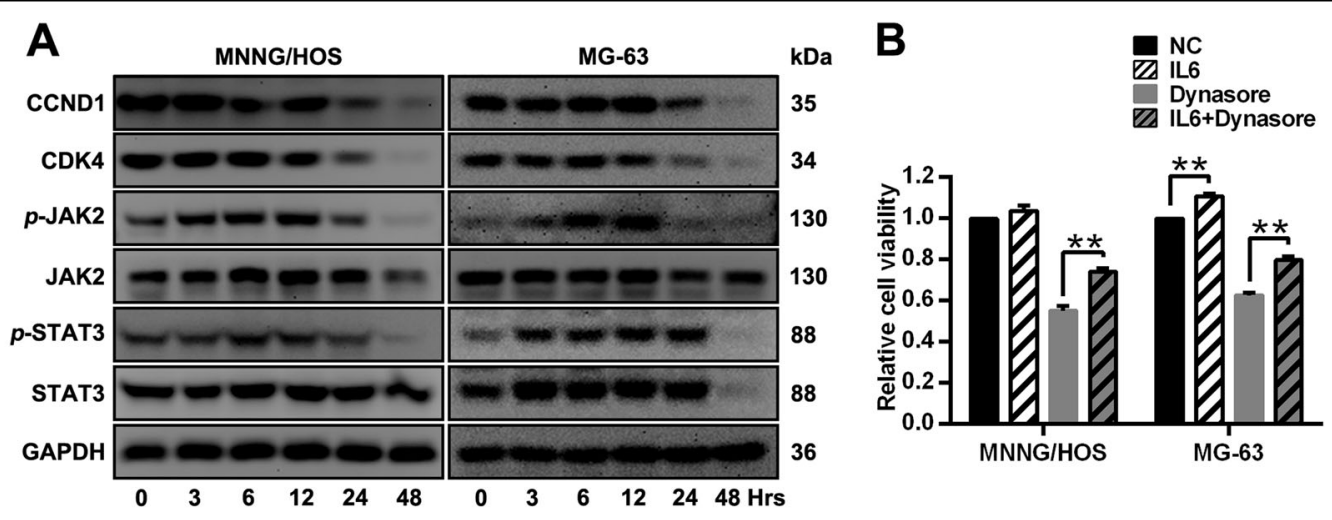

C

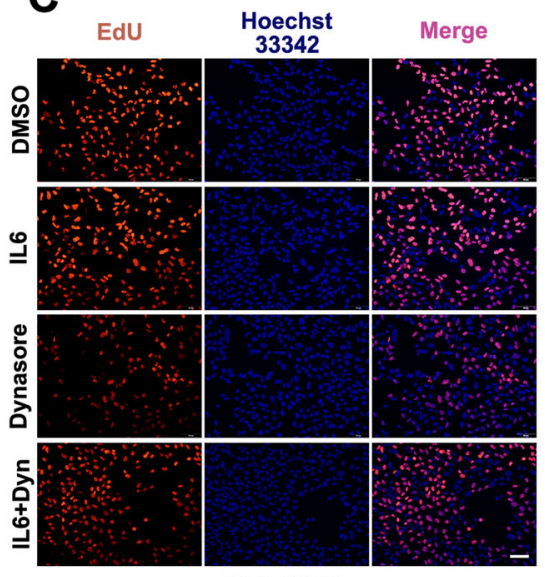

D
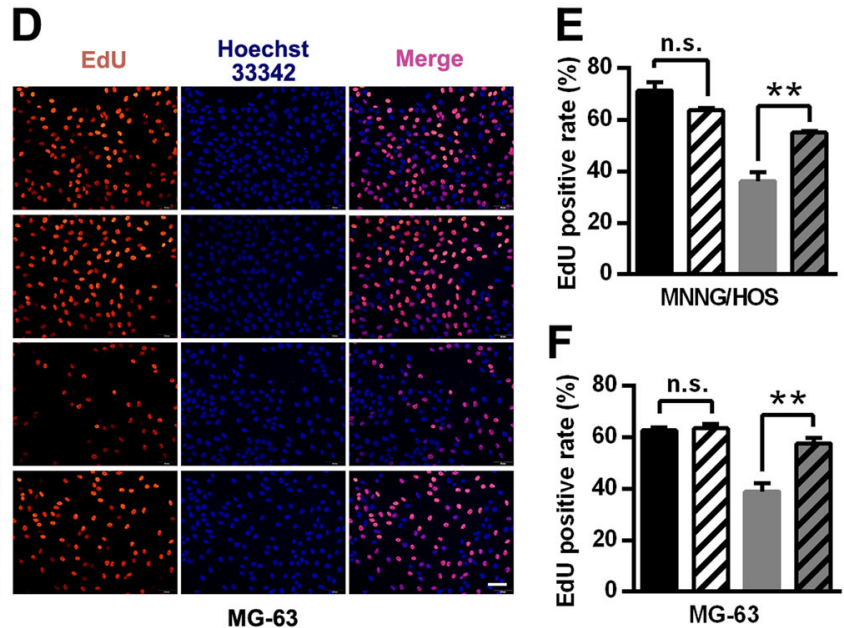

Fig. 9 Dynasore exert anti-OS effects partially by STAT3 signaling pathway. a The expression of CCND1, CDK4, p-JAK2, JAK2, p-STAT3, and STAT3 were detected by western blot after treated with dynasore for $0,3,6,12,24$, and $48 \mathrm{~h}$. $\mathbf{b}$ The cell viability of OS cells after treated with IL-6 $(50 \mathrm{ng} / \mathrm{ml})$ followed by dynasore exposure. After activation of STAT3 pathway by IL-6, cell proliferations were analyzed by EdU staining (MNNG/HOS (c and e) and MG-63 cells (d and f)). ${ }^{*} p<0.05$ and ${ }^{* *} p<0.01$ vs. DMSO group. Hrs, hours. Scale bar: $50 \mu \mathrm{m}$

However, despite the unremitting efforts of researchers in the last four decades, the survival rate still remains unsatisfactory, especially in patients with systemic metastasis or local relapse ${ }^{2,23-25}$. Drugs that widely used in OS chemotherapy generally develop side effects and cause injuries in normal tissues of cancer patients. Worse still, about $35-45 \%$ patients turn out to be unresponsive or resistant to these drugs, which leads to treatment failure ${ }^{2,26}$. In the present study, we demonstrated the antiOS potential of dynasore for the first time in vitro and in vivo model. By combining dynasore and cisplatin, we found that dynasore enhanced the anti-tumor effect of cisplatin.

Cell cycle is a sequence of highly regulated events that allows a cell to grow, duplicate its genetic material, and divide into two daughter cells ${ }^{27}$. The homeostasis of the cell cycle regulatory mechanisms is deranged in cancer cells, and consequently, leading to unscheduled malignant proliferation, which is considered as one of the proverbial features of malignancies ${ }^{28}$. In G0/G1 phase, the activity of
E2F, which is critical in gene transcription, was repressed by hypophosphorylated $\mathrm{pRb}$. Once triggered by G1-S cell cycle transitive signaling, the increasingly synthesized CCND binds to cyclin-dependent kinases (CDK4 or CDK6). Then, the CCND-CDK4/6 complexes phosphorylate $\mathrm{pRb}$ to release the $\mathrm{pRb}$ from E2F-DP complexes and initiate the activation of transcription ${ }^{27,29,30}$. We found that dynasore suppressed cell proliferation and induced G0/G1 phase arrest of OS cell lines. Furthermore, dynasore reduced the expression of $\mathrm{pRb}, \mathrm{CCND} 1$, and CDK4. These results indicate that dynasore somehow inhibited CCND1 and CDK4 expression so that CCND1-CDK4 complexes decreased, which leads to hypophosphorylation of $\mathrm{pRb}$ and block G1-S transition. Since identified, dynasore was widely used in the researches of endocytosis and macropinocytosis as a dynamin inhibitor $^{11,12,31-33}$. In the latest reports, dynasore was found to be able to repress cell proliferation, migration of lung cancer cell lines in vitro ${ }^{18,19}$, and, consist with our results, dynasore augmented the anti-cancer effects of cisplatin ${ }^{18}$. 
In the present study, no sufficient evidences were found in dynasore induced apoptosis of OS cells. However, dynasore induced apoptosis and mitochondrial dysfunction in lung cancer cells. Moreover, dynasore induced $\mathrm{S}$ phase cell cycle arrest in HCC827 and H1650 cells, while did not affect the cell cycle distribution of A549 cells $^{19}$. These differences indicate the diverse roles of dynasore in different cancer cells.

Abnormally elevated cell migration and invasion gives OS cells the intensive ability of systemic metastasis and locally aggression, which is responsible for poor prognosis and death ${ }^{2} \mathrm{~N}$-cadherin is a transmembrane protein which mediates intercellular adhesion and involves in transendothelial migration. In Epithelial-Mesenchymal Transition (EMT) process, the expression of $\mathrm{N}$-cadherin is increased and balanced by E-cadherin down-regulation. The transitioned cells acquire the affinity to mesenchymal cells and enhance the expression of proteases such as matrix metalloproteinases (MMPs), and, finally facilitate the capacity of migration and invasion ${ }^{34,35}$. The MMPs are a family of zinc-containing endopeptidases which are capable of degrading all kinds of extracellular matrix (ECM) protein, and play important roles in physiological and pathological processes ${ }^{36,37}$. Among these MMPs, MMP-2, and MMP-9 were confirmed to be crucial in cancer metastasis and aggression for their ability of remodeling basement membrane via degrading Type IV collagen $^{38,39}$. Chung et al. showed that elevated MMP-2 activity stimulated by TGF- $\beta 1$ was partially impaired when pretreated with dynasore ${ }^{40}$. Wang et al found dynasore inhibited the migration of lung cancer cells and down-regulated active MMP-9 level ${ }^{19}$. Consistently, our results showed that dynasore treatment resulted in suppressed cell migration and invasion, and reduced MMP-2 protein level of OS cells. However, western blot found no evidences of dynasore mediated MMP-9 or N-cadherin down-regulation. Therefore, dynasore inhibited the migration and invasion of OS mainly through downregulation of MMP-2, but not MMP-9 or N-cadherin.

STAT3 is a member of STATs (Signal Transducers and Activators of Transcriptions) family and acts as signal messagers and transcription factors. After activated by cytokines or growth factors, STAT3s are phosphorylated to form STAT3 dimer and travels from plasma membrane to nucleus, and then initiates the transcription of downstream target genes such as CCND1, CCNB, cdc2, surviving, Bcl-2, Mcl-1, MMP-1, and MMP- $2^{41-44}$. In cancer cells, constitutive activation of STAT3 breaks the strict control mechanism of downstream gene transcription and involves in tumor growth, survival, invasion, metastasis, and angiogenesis ${ }^{45,46}$. Literatures have shown that overexpression and aberrant activation of STAT3 contributes to the tumorigenesis, progression, and poor prognosis of several cancers including $\mathrm{OS}^{47-50}$. Besides, growing concentrations have focused on novel drugs investigation by treating STAT3 as a therapy target ${ }^{51-53}$. Our study showed that dynasore treatment inhibited cell proliferation, migration, invasion and tumorigenesis of OS, decreased the expression of $p$-STAT3 in vitro and in xenograft mouse model. At the meantime, total STAT3 protein expression was found suppressed by dynasore in vitro and in vivo. By using real-time PCR, we found that the mRNA expression of STAT3 in MNNG/HOS and MG-63 was not affected by dynasore, which indicating that the protein expression of STAT3 was inhibited at post-transcriptional level. The post-transcriptional modification of STAT3 includes tyrosine phosphorylation, serine phosphorylation, acetylation, methylation, and oxidation $^{54}$. STAT3 deacetylation can be activated by NAD-dependent silent information regulator protein (SIRT) 1, and results STAT3 destabilization and degradation ${ }^{54-56}$. By treating with dynasore, the endocytosis of cells is repressed, which might block the cellular nutrients transportation and, consequently, activate regulator proteins like SIRT1 to initiate STAT3 deacetylation. Literatures showed that most STAT3 inhibitors $53,57,58$ functioned by repressing the activation of STAT3. Our study indicated that dynasore served as a STAT3 pathway inhibitor in OS, which supplement the list of inhibitors ${ }^{59,60}$ suppressing both expression and phosphorylation of STAT3. In addition, the phosphorylation of JAK2, which can activate STAT family, and downstream target genes (CCND1, MMP-2) of STAT3, was also downregulated in dynasore exposed group. IL- 6 is the most well known activator of STAT3 pathway ${ }^{61,62}$. In this study, we activated the STAT3 pathway by using IL-6 and found that the anti-proliferation effect of dynasore on OS cells was dramatically attenuated (both in CCK- 8 assay and EdU staining assay). These evidences suggest that dynasore exerts anti-tumor effect, or at least anti-proliferation effect, in OS via STAT3 signaling pathway.

Previous studies have indicated that p38 MAPK, MAPK-ERK, PI3K-Akt, and SAPK/JNK signaling pathways are involved in cell proliferation ${ }^{20,63-66}$. In our study, we found that dynasore did not affect the expression and activation of ERK1/2, Akt or SAPK/JNK, indicating that MAPK-ERK and PI3K-Akt and SAPK/JNK signaling pathways might not involve in dynasore induced anti-OS effect. The role of p38 MAPK pathway in proliferation was ambiguous ${ }^{66}$. Most studies suggested that p38 activation promoted cell proliferation ${ }^{64,67,68}$, while another reports showed opposite results ${ }^{65}$. Here, we demonstrated that the phosphorylation level of p38 was elevated in dynasore treated OS cells. Interestingly, by using SB239063, a p38-specific inhibitor, the anti-proliferation effect of dynasore was enhanced. Collectively, we hypothesize that when dynasore significantly inhibited cell proliferation, p38 MAPK pathway was activated as a 
negative regulatory mechanism to lessen the anti-tumor effect of dynasore on OS cells. Therefore, if possible, p38 MAPK inhibitor should be used as an adjuvant of dynasore in the treatment of OS in the future.

In summary, to our knowledge, this is the first research that studies the anti-tumor effect of dynasore on OS. Based on our finding, we exhibited that dynasore possessed anti-OS ability in vitro and in vivo. Besides, dynasore significantly enhanced the anti-tumor effects of cisplatin without inducing nephrotoxicity and hepatotoxicity. Mechanistically, we found that dynasore exerted anti-tumor effects, or at least anti-proliferation effect, in OS via STAT3 signaling pathway. Collectively, our study reveals the anti-tumor effects of dynasore on OS, which may supplement the candidate chemotherapy drug list, and reduce cisplatin-mediated side effects by decreasing dosage via drug combination.

\section{Acknowledgements}

This study was supported by the National Key Research and Development Program of China (2016YFC1100100), the Major Research Plan of National Natural Science Foundation of China (No. 91649204), and Nature Science Foundation of Hubei Province (2018CFB118).

\section{Conflict of interest}

The authors declare that they have no conflict of interest.

\section{Publisher's note}

Springer Nature remains neutral with regard to jurisdictional claims in published maps and institutional affiliations.

Supplementary Information accompanies this paper at (https://doi.org/ 10.1038/s41419-019-1917-2).

Received: 23 May 2019 Revised: 23 August 2019 Accepted: 26 August 2019 Published online: 18 September 2019

\section{References}

1. Mirabello, L., Troisi, R. J. \& Savage, S. A. Osteosarcoma incidence and survival rates from 1973 to 2004: data from the Surveillance, Epidemiology, and End Results Program. Cancer 115, 1531-1543 (2009).

2. Luetke, A., Meyers, P. A., Lewis, I. \& Juergens, H. Osteosarcoma treatment where do we stand? A state of the art review. Cancer Treat. Rev. 40, 523-532 (2014).

3. Geller, D. S. \& Gorlick, R. Osteosarcoma: a review of diagnosis, management, and treatment strategies. Clin. Adv. Hematol. Oncol. 8, 705-718 (2010).

4. Durfee, R. A., Mohammed, M. \& Luu, H. H. Review of osteosarcoma and current management. Rheumatol. Ther. 3, 221-243 (2016).

5. Florea, A. M. \& Busselberg, D. Cisplatin as an anti-tumor drug: cellular mechanisms of activity, drug resistance and induced side effects. Cancers $\mathbf{3}$, 1351-1371 (2011)

6. Dasari, S. \& Tchounwou, P. B. Cisplatin in cancer therapy: molecular mechanisms of action. Eur. J. Pharmacol. 740, 364-378 (2014).

7. Manohar, S. \& Leung, N. Cisplatin nephrotoxicity: a review of the literature. J. Nephrol. 31, 15-25 (2018).

8. Skinner, R. et al. Cisplatin dose rate as a risk factor for nephrotoxicity in children. Br. J. Cancer 77, 1677-1682 (1998).

9. Reece, P. A., Stafford, I., Russell, J., Khan, M. \& Gill, P. G. Creatinine clearance as a predictor of ultrafilterable platinum disposition in cancer patients treated with cisplatin: relationship between peak ultrafilterable platinum plasma levels and nephrotoxicity. J. Clin. Oncol. 5, 304-309 (1987).
10. Stewart, D. J. et al. Association of cisplatin nephrotoxicity with patient characteristics and cisplatin administration methods. Cancer Chemother. Pharmacol. 40, 293-308 (1997).

11. Macia, E. et al. Dynasore, a cell-permeable inhibitor of dynamin. Developmental Cell 10, 839-850 (2006).

12. Preta, G., Cronin, J. G. \& Sheldon, I. M. Dynasore - not just a dynamin inhibitor. Cell Commun. Signal.: CCS 13, 24 (2015).

13. Li, G. et al. Dynasore improves motor function recovery via inhibition of neuronal apoptosis and astrocytic proliferation after spinal cord injury in rats. Mol. Neurobiol. 54, 7471-7482 (2017).

14. Song, H. L. et al. beta-Amyloid is transmitted via neuronal connections along axonal membranes. Ann. Neurol. 75, 88-97 (2014).

15. Gao, D. et al. Dynasore protects mitochondria and improves cardiac lusitropy in Langendorff perfused mouse heart. PLOS ONE 8, e60967 (2013).

16. Yamada, H. et al. Dynasore, a dynamin inhibitor, suppresses lamellipodia formation and cancer cell invasion by destabilizing actin filaments. Biochem. Biophys. Res. Commun. 390, 1142-1148 (2009).

17. Otsuka, A. et al. Dynamin 2 is required for actin assembly in phagocytosis in Sertoli cells. Biochem. Biophys. Res. Commun. 378, 478-482 (2009).

18. Shen, F. et al. Dynasore suppresses proliferation and induces apoptosis of the non-small-cell lung cancer cell line A549. Biochem. Biophys. Res. Commun. 495, 1158-1166 (2018).

19. Wang, T. et al. Dynasore-induced potent ubiquitylation of the exon 19 deletion mutant of epidermal growth factor receptor suppresses cell growth and migration in non-small cell lung cancer. Int. J. Biochem. Cell Biol. 105, 1-12 (2018).

20. Luo, X. et al. Puerarin exerts a delayed inhibitory effect on the proliferation of cardiomyocytes derived from murine ES cells via slowing progression through G2/M phase. Cell. Physiol. Biochem. 38, 1333-1342 (2016).

21. Xiong, L. L. et al. Administration of SB239063, a potent p38 MAPK inhibitor, alleviates acute lung injury induced by intestinal ischemia reperfusion in rats associated with AQP4 downregulation. Int. Immunopharmacol. 38, 54-60 (2016).

22. Pan, X., Wang, C., Li, Y., Zhu, L. \& Zhang, T. Protective autophagy induced by physcion suppresses hepatocellular carcinoma cell metastasis by inactivating the JAK2/STAT3 Axis. Life Sci. 214, 124-135 (2018).

23. Omer, N. et al. Phase-ll trials in osteosarcoma recurrences: a systematic review of past experience. Eur. J. Cancer 75, 98-108 (2017).

24. Meyers, P. A. et al. Osteosarcoma: a randomized, prospective trial of the addition of ifosfamide and/or muramyl tripeptide to cisplatin, doxorubicin, and high-dose methotrexate. J. Clin. Oncol. 23, 2004-2011 (2005).

25. Anninga, J. K. et al. Chemotherapeutic adjuvant treatment for osteosarcoma: where do we stand? Eur. J. Cancer 47, 2431-2445 (2011).

26. Hattinger, C. M., Pasello, M., Ferrari, S., Picci, P. \& Serra, M. Emerging drugs for high-grade osteosarcoma. Expert Opin. Emerg. Drugs 15, 615-634 (2010).

27. Poon, R. Y. Cell cycle control: a system of interlinking oscillators. Methods Mol. Biol. 1342, 3-19 (2016).

28. Hanahan, D. \& Weinberg, R. A. Hallmarks of cancer: the next generation. Cell 144, 646-674 (2011).

29. Wang, F. et al. microRNA-16-5p enhances radiosensitivity through modulating Cyclin D1/E1-pRb-E2F1 pathway in prostate cancer cells. J. Cell. Physiol. 234, 13182-13190 (2019).

30. Liu, T., Hou, L. \& Huang, Y. EZH2-specific microRNA-98 inhibits human ovarian cancer stem cell proliferation via regulating the pRb-E2F pathway. Tumour Biol. 35, 7239-7247 (2014)

31. Zhao, T. et al. Entry of sapelovirus into IPEC-J2 cells is dependent on caveolaemediated endocytosis. Virol. J. 16, 37 (2019).

32. He, J. et al. Membrane fusogenic lysine type lipid assemblies possess enhanced NLRP3 inflammasome activation potency. Biochem. Biophys. Rep. 18, 100623 (2019).

33. Ghose, J. et al. Daratumumab induces CD38 internalization and impairs myeloma cell adhesion. Oncoimmunology 7, e1486948 (2018).

34. Theveneau, E. \& Mayor, R. Cadherins in collective cell migration of mesenchymal cells. Curr. Opin. Cell Biol. 24, 677-684 (2012).

35. Lamouille, S., $\mathrm{Xu}$, J. \& Derynck, R. Molecular mechanisms of epithelialmesenchymal transition. Nat. Rev. Mol. Cell Biol. 15, 178-196 (2014).

36. Gialeli, C., Theocharis, A. D. \& Karamanos, N. K. Roles of matrix metalloproteinases in cancer progression and their pharmacological targeting. FEBS J. 278, 16-27 (2011). 
37. Amar, S., Smith, L. \& Fields, G. B. Matrix metalloproteinase collagenolysis in health and disease. Biochimica et. Biophysica Acta Mol. Cell Res. 1864, 1940-1951 (2017)

38. Yao, Z. et al. MMP-2 together with MMP-9 overexpression correlated with lymph node metastasis and poor prognosis in early gastric carcinoma. Tumour Biol. 39, 1010428317700411 (2017).

39. Ma, F. et al. Matrix metalloproteinase 9 and prostate cancer risk: a metaanalysis of 1059 participants. Minerva urologica e nefrologica $=\mid$ tal. J. Urol. Nephrol. 69, 324-329 (2017).

40. Chung, C. L. et al. Dynasore, a dynamin inhibitor, induces PAl-1 expression in MeT-5A human pleural mesothelial cells. Am. J. Respiratory Cell Mol. Biol. 40 692-700 (2009).

41. Bousoik, E. \& Montazeri Aliabadi, H. "Do We Know Jack" About JAK? A Closer Look at JAK/STAT Signaling Pathway. Front. Oncol. 8, 287 (2018).

42. Mali, S. B. Review of STAT3 (signal transducers and activators of transcription) in head and neck cancer. Oral. Oncol. 51, 565-569 (2015).

43. Bo, C., Wu, Q., Zhao, H., Li, X. \& Zhou, Q. Thymosin alpha1 suppresses migration and invasion of PD-L1 high-expressing non-small-cell lung cancer cells via inhibition of STAT3-MMP2 signaling. OncoTargets Ther. 11, 7255-7270 (2018).

44. Jiang, D. et al. Long Chain Non-Coding RNA (IncRNA) HOTAIR Knockdown Increases miR-454-3p to Suppress Gastric Cancer Growth by Targeting STAT3/ Cyclin D1. Med. Sci. Monit. 25, 1537-1548 (2019).

45. Yu, H., Pardoll, D. \& Jove, R. STATs in cancer inflammation and immunity: a leading role for STAT3. Nat. Rev. Cancer 9, 798-809 (2009).

46. Aggarwal, B. B. et al. Signal transducer and activator of transcription-3, inflammation, and cancer: how intimate is the relationship? Ann. N. Y. Acad. Sci. 1171, 59-76 (2009).

47. Sheen-Chen, S. M., Huang, C. C., Tang, R. P., Chou, F. F. \& Eng, H. L. Prognostic value of signal transducers and activators of transcription 3 in breast cancer. Cancer Epidemiol., Biomark. Prev. 17, 2286-2290 (2008).

48. Horinaga, M. et al. Clinical and pathologic significance of activation of signal transducer and activator of transcription 3 in prostate cancer. Urology $\mathbf{6 6}$, 671-675 (2005).

49. Ryu, $K$. et al. Activation of signal transducer and activator of transcription 3 (Stat3) pathway in osteosarcoma cells and overexpression of phosphorylatedStat3 correlates with poor prognosis. J. Orthop. Res. 28, 971-978 (2010).

50. Wang, Y. C. et al. Clinical value of signal transducers and activators of transcription 3 (STAT3) gene expression in human osteosarcoma. Acta Histochemica 113, 402-408 (2011).

51. Yan, J. et al. Inhibition of the JAK2/STAT3 signaling pathway exerts a therapeutic effect on osteosarcoma. Mol. Med. Rep. 12, 498-502 (2015).

52. Chai, E. Z. et al. Targeting transcription factor STAT3 for cancer prevention and therapy. Pharmacol. Therapeutics 162, 86-97 (2016).
53. Oi, T. et al. STAT3 inhibitor, cucurbitacin I, is a novel therapeutic agent for osteosarcoma. Int. J. Oncol. 49, 2275-2284 (2016).

54. Avalle, L., Camporeale, A., Camperi, A. \& Poli, V. STAT3 in cancer: A double edged sword. Cytokine 98, 42-50 (2017).

55. Chen, Y. et al. SIRT1 downregulated FGB expression to inhibit RCC tumorigenesis by destabilizing STAT3. Exp. Cell Res., https://doi.org/10.1016/j. yexcr.2019.06.011 (2019).

56. Nie, Y. et al. STAT3 inhibition of gluconeogenesis is downregulated by SirT1. Nat. Cell Biol. 11, 492-500 (2009).

57. Park, K. R. et al. 4-Methoxydalbergione suppresses growth and induces apoptosis in human osteosarcoma cells in vitro and in vivo xenograft model through down-regulation of the JAK2/STAT3 pathway. Oncotarget 7, 6960-6971 (2016).

58. $\mathrm{Hu}, \mathrm{H}$. et al. Lycorine exerts antitumor activity against osteosarcoma cells in vitro and in vivo xenograft model through the JAK2/STAT3 pathway. OncoTargets Ther. 12, 5377-5388 (2019).

59. Zuo, D. et al. Inhibition of STAT3 blocks protein synthesis and tumor metastasis in osteosarcoma cells. J. Exp. Clin. Cancer Res. 37, 244 (2018).

60. Han, D. et al. Napabucasin, a novel STAT3 inhibitor suppresses proliferation, invasion and stemness of glioblastoma cells. J. Exp. Clin. Cancer Res. 38, 289 (2019).

61. Yu, H., Lee, H., Herrmann, A., Buettner, R. \& Jove, R. Revisiting STAT3 signalling in cancer: new and unexpected biological functions. Nat. Rev. Cancer 14, 736-746 (2014).

62. Servais, F. A. et al. Modulation of the IL-6-signaling pathway in liver cells by miRNAs targeting gp130, JAK1, and/or STAT3. Mol. Ther. Nucleic Acids 16, 419-433 (2019).

63. Wang, J., Pan, Y., Cao, Y., Zhou, W. \& Lu, J. Salidroside regulates the expressions of IL-6 and defensins in LPS-activated intestinal epithelial cells through NF-kappaB/MAPK and STAT3 pathways. Iran. J. Basic Med. Sci. 22, 31-37 (2019).

64. Lin, Z. et al. Columbamine suppresses hepatocellular carcinoma cells through down-regulation of PI3K/AKT, p38 and ERK1/2 MAPK signaling pathways. Life Sci. 218, 197-204 (2019).

65. Chen, L. et al. Deguelin induces apoptosis in colorectal cancer cells by activating the p38 MAPK pathway. Cancer Manag. Res. 11, 95-105 (2019).

66. Wagner, E. F. \& Nebreda, A. R. Signal integration by JNK and p38 MAPK pathways in cancer development. Nat. Rev. Cancer 9, 537-549 (2009).

67. Xiao, W. et al. Rafoxanide, an organohalogen drug, triggers apoptosis and cell cycle arrest in multiple myeloma by enhancing DNA damage responses and suppressing the p38 MAPK pathway. Cancer Lett. 444, 45-59 (2019).

68. Olson, J. M. \& Hallahan, A. R. p38 MAP kinase: a convergence point in cancer therapy. Trends Mol. Med. 10, 125-129 (2004). 